\title{
SOBRE MODELOS DE GESTIÓN UNIVERSITARIA
}

\section{Gobierno y gobernabilidad universitarios}

El gobierno institucional en las universidades se refiere a la generación, fundamentación, legitimación y distribución del poder. La conversión del poder en autoridad es una de las principales funciones de la gerencia universitaria, entendiendo por autoridad aquel poder conferido por liderazgo y legitimado por las normas vigentes en una comunidad determinada. El problema de la institución universitaria, que origina frecuentes focos de conflicto, es la coexistencia de diferentes legitimidades y, por ende, autoridades, dependiendo del tipo de institución y de sus fines declarados. Al mismo tiempo, las universidades muestran una composición heterogénea dentro de sus comunidades, incluyendo un grupo por definición transitorio, los estudiantes y grupos de presión que obedecen a lealtades ajenas a las estrictamente institucionales (corporativas, profesionales o políticas). Armonizar estas distintas racionalidades y sus legitimaciones, a menudo antagónicas, plantea problemas que son propios de la institucionalidad universitaria.

Los desafíos para una recta gerencia son múltiples. Algunas de las tareas más claras son las siguientes: a) formular metas a mediano y largo plazo, b) establecer prioridades para su cumplimiento efectivo, c) delegar adecuadamente el poder en autoridades legítimas (esto es, reconocidas según las prácticas sociales vigentes en el grupo), d) controlar el desarrollo de las tareas, e) mantener la imagen pública, f) asegurar la viabilidad financiera y política de la comunidad, y g) proyectar la institución en el concierto social.

Hay que distinguir dos planos en la ejecución de estas tareas. El plano estratégico corresponde a los cuerpos y/o directivos 
superiores y se concentra en los lineamientos generales. El plano táctico considera la logística y los problemas de la realización concreta y debe tener la flexibilidad suficiente para adaptar con prudencia los lineamientos generales a las cambiantes circunstancias del entorno. En las instituciones no estructuradas es frecuente que ambos planos de acción se confundan, sobrecargando la alta gerencia con detalles de gestión o demandando de la administración menor decisiones que involucran un pensamiento global. Este error no es infrecuente en universidades complejas, debido, precisamente, a la magnitud o importancia de los subgrupos que las constituyen (fuerte administración, numeroso cuerpo docente, multitudes de estudiantes).

Gobernabilidad se entiende aquí como la condición en la cual, bajo un determinado modelo de gestión declarado y aceptado, el estado real de la institución se acerca a la máxima eficacia y efectividad. Según el contexto histórico en que se encuentre una institución, y los condicionantes externos y desafíos emergentes, la gobernabilidad será alta o baja, buena o mala, apropiada o inapropiada. La excelencia en gobernabilidad tiene que ver tanto con el cumplimiento de estándares como con la satisfacción de metas y prioridades en una forma que satisfaga a la comunidad y a su dirigencia.

\section{Heterogeneidad institucional, interna y global}

Por definición, las instituciones universitarias son heterogéneas en su composición y en sus metas sociales (Lolas, 1996). Esta heterogeneidad desemboca en una polisemia del término "universidad" y en múltiples significados para palabras tales como "autoridad", "liderazgo", "negocio", "eficiencia", y otras muchas usadas por miembros de subgrupos dentro de la institución que, a menudo, desarrollan subculturas organizacionales contrapuestas y potencialmente conflictivas. 
Existe una heterogeneidad de personas. Según los papeles sociales, suele distinguirse entre personal profesional (a veces llamado académico), personal administrativo y de apoyo y una población variable de estudiantes de muy diverso tipo y condición, de acuerdo con edad, aspiraciones, compromiso institucional, régimen horario y situación social.

La configuración de una institución heterogénea en su interior se ve afectada, además, por diversidades macroestructurales que permiten tipificar a las instituciones desde diversos puntos de vista.

Suele usarse a veces un criterio histórico, distinguiendo instituciones tradicionales, fundadas antes de una cierta fecha o evento histórico crucial, instituciones nuevas e instituciones derivadas de otras. También es posible emplear un criterio geográfico, diferenciando instituciones de provincia o de las capitales de país, instituciones ligadas a una región o área e instituciones de alcance nacional o internacional. Existe también un criterio confesional, según orientaciones doctrinarias definidas por el grupo que crea o controla una universidad.

Todos estos criterios son útiles para el propósito de la taxonomía. Para los fines de este análisis, es conveniente examinar una tipificación basada en el origen del poder y los modos de su transformación en autoridad institucional, que es el poder legitimado por normas validadas por la comunidad.

Una fuente de poder es, sin duda, la propiedad institucional. Así, hay instituciones que pertenecen a consorcios empresariales, confesiones religiosas o grupos políticos. También es fuente de poder transformable en autoridad la tradición institucional, pues señala quiénes están capacitados para ejercer funciones de dirigencia. Asimismo, es posible señalar al consenso entre grupos o personas como fuente de poder, lo que naturalmente lleva a problemas de definición sobre quiénes están facultados para dialogar 
o negociar. Existe poder, además, derivado en ocasiones de fuerzas externas que actúan sobre las instituciones o bien de ideologías consideradas nucleares.

El origen del poder (y, por ende, de la autoridad) no es irrelevante al considerar los diversos grupos o estamentos que componen la institución. Muchas veces la aceptación de las normas encuentra resistencias derivadas justamente del origen del poder, lo que permite cuestionar la autoridad que de él emana o justifica acciones contrarias a los lineamientos institucionales. Una adecuada ingeniería institucional se entiende a veces como el diseño de las condiciones para consensos fáciles, lo que significa seleccionar los miembros de la institución (permanentes o transitorios) de acuerdo con criterios relativamente uniformes. En general, las instituciones con homogeneidad interior alta adoptan ciertos modelos de gestión muy similares a los de las empresas privadas, con claros límites demarcatorios entre "lo de adentro" y "lo de afuera", y formas de "lealtad" que contrastan con las de instituciones con elevada heterogeneidad estructural. El poder originado en las tradiciones suele perpetuar formas administrativas altamente resistentes al cambio, en contraste con aquellas instituciones en las cuales el poder deriva de algún tipo de consenso, salvo que éstas copien formas administrativas por motivos cosméticos. Las tareas de la dirigencia universitaria debidamente legitimada (reseñadas antes) se realizan diversamente según el modelo de gestión escogido, como examinaremos en seguida (Lolas, 1996, pp. 75-89).

\section{Modelos de gestión universitaria}

La expresión "modelo de gestión" suele usarse muy laxamente para caracterizar la gerencia universitaria y, a menudo, se confunde con consignas doctrinarias o con efectividad financiera, Scilla y Caribdis de la tarea de dirigir universidades. Ambos extremos son perjudiciales si llevan a orientaciones exclusivas y excluyentes, y no son entendidos como alternativas que a veces pueden coexistir y otras aplicarse secuencialmente según los contextos. 
Para definir un modelo de gestión nos apoyamos en las tareas definidas antes, esto es, formulación de metas, establecimiento de prioridades, delegación de poder, proyección externa y control de los procesos.

Existe, talvez en forma clásica, un modelo autoritario en la gestión universitaria, muchas veces respaldado por la noción de que las tareas intelectuales son, por definición, jerárquicas y elitistas. El sistema social de la ciencia, por ejemplo, por mucho que se diga en contrario, es altamente aristocrático, en el sentido de que premia a los mejores (por cualquier criterio que sea definido lo mejor) y desplaza a los menos buenos. Al trasladar el modelo social de esa actividad a la universidad, se tiene el intento de una república platónica en pequeño con los "sabios" a la cabeza y el resto en obsecuente obediencia.

El modelo autoritario, sin embargo, es invocado también por aquéllos que rigen instituciones derivadas de algún grupo cohesionado por ideología, religión o finanzas, en cuyo caso suele disfrazárselo con una cosmética verbal que no declare su carácter. Una forma de efectuarlo es haciendo recaer el peso decisional en cuerpos colegiados, cuyas formas de generación son controladas por la elite dominante.

Lo nuclear del modelo autoritario es que la fijación de metas, el establecimiento de prioridades, el control de los desarrollos y la presencia externa dependen de un estilo "top to bottom" con muy escasa retroalimentación por parte de miembros de la comunidad sin autoridad formal.

Frente al modelo autoritario cabría distinguir, con fines heurísticos, un modelo participativo, en el cual el ejercicio de la autoridad está atemperado por la práctica de consensos o de disensos controlables. Es evidente que una universal disensión permanente hace ingobernable cualquier institución y son justamente los límites del disenso permitido y legal los que permiten 
evaluar la gobernabilidad. Aquí caben diversas posibilidades, desde una participación irrestrictamente universal hasta una acotada a ciertos subgrupos o jerarquías institucionales. Lo esencial en el modelo, en cualquiera de sus variantes, es que el tiempo decisional es más prolongado y exige mayor cantidad de argumentación que en la versión autoritaria. La forma plenamente democrática de universidad se ha dado en América Latina bajo denominaciones distintas, desde cogobierno hasta electoralismo, y solamente puede ser enjuiciada atendiendo a los resultados de su cumplimiento de metas.

Existe un modelo empresarial de gestión, en el cual la institución y sus autoridades se orientan a la producción de bienes y servicios transables en mercados de dinero, prestigio, influencia o poder político. En estos casos, la membrana que divide el "adentro" del "afuera" suele ser relativamente impermeable a la influencia ideológica, como no sea aquella que impacta en prácticas mercantiles o posicionamiento estratégico. La generación de la autoridad depende de los propietarios de la institución -personas o empresas- y su éxito o fracaso se mide a través de indicadores usados en el contexto de la empresa. Así como el modelo puramente "científico" de la universidad introduce unas prácticas sociales propias de un sistema social específico y limitado, también aquí se replica un modelo que, al igual que el otro, puede ser exitoso en algunas dimensiones, pero no dará buena cuenta de la heterogeneidad estructural y la diversidad de grupos que constituyen las universidades en el presente.

Existen varios otros modelos de gestión, según enseña la observación empírica. Por ejemplo, en algunas instituciones existe una predilección por una forma que puede denominarse "demagógico/amorfa", en la cual hay un cierto oportunismo decisional que a veces se confunde con audacia empresarial, satisfacciones a grupos políticos o seudoingeniería institucional. A menudo, la ausencia de profesionalismo en los docentes o profesionales que asumen posiciones de autoridad en el medio 
universitario se inclina hacia este tipo de gestión, caracterizado por un cierto desprecio de las reglas del buen negocio, unas componendas a menudo fugaces con la violencia de los subgrupos internos y ocasionales destellos de buena fortuna que son muy publicitados. Paradójicamente, cuando las instituciones universitarias se instalan en este modelo, sus miembros suelen mantenerlo, porque aparentemente incorpora prácticas participativas directas, clientelismo disfrazado de mérito académico y bonanzas financieras ocasionales.

También es observable un modelo que podemos denominar "conflictual/feudal", en el cual la institución mayor, en cuanto tal, solamente existe en unidades cuasi autónomas que usan el nombre común (al modo del "franchising" o franquicia), pero compiten entre sí por prestigios y prebendas internos y externos. En estos casos, la autoridad corporativa suele reducirse a un papel mediador y representativo, en el cual se copian prácticas de instituciones cohesionadas o se adopta cosméticamente su lenguaje, pero en realidad se trata de un estado de deriva y anarquía institucional, con ocasionales hegemonías y predominios disciplinarios, económicos o administrativos.

Es necesario advertir que la fenomenología de las formas de gestión no deriva automáticamente del origen del poder, pues puede haber instituciones gestadas al amparo de una racionalidad empresarial que avanzan hacia un modelo participativo propio de instituciones estatales y, a la inversa, instituciones públicas regidas con mentalidad empresarial. De ello cabe deducir que la simple caracterización de las instituciones sólo sobre la base de los criterios antes expuestos, concernientes a origen y legitimidad del poder, no basta para los fines de estudiar sus formas reales de gerencia y orientación. En Chile tenemos casos de instituciones privadas con "espíritu público" e instituciones públicas con metas de rentabilidad económica que compiten con otras netamente empresariales (Dittborn, Lolas y Salazar, 2004). 
En pocas instituciones sociales se produce, como en las universidades, un permanente conflicto de racionalidades; deriva de sus audiencias numerosas y de sus diferentes papeles sociales. Quienes trasladan a la universidad el elitismo del sistema social de la ciencia lo hacen con el convencimiento de que esta institución tiene por misión cultivar la ciencia ignorando sus otras misiones sociales. La idea del instituto docente preparador de las burocracias estatales o generador de los cuadros directivos de la empresa adopta matices en los distintos estadios de evolución de la institucionalidad universitaria. Los ideales universitarios en torno a la equidad social o al papel de abogacía que cabe a los intelectuales y a los trabajadores de la cultura son centrales en más de algún intento por proletarizar la universidad e insertarla entre las instituciones útiles a la universalización del saber en una comunidad (Lolas, 2004a).

Lo que fluye de estas consideraciones es la polisemia del término universidad (Lolas, 1997), la variedad de tareas que enfrenta su adecuada dirección y la crucial importancia que tiene estudiar el origen, distribución y delegación de los poderes que legitiman las formas de gestión y, finalmente, la eficiencia, eficacia y dignidad de la institución universitaria (Lolas, 2004b).

\section{Referencias bibliográficas}

Dittborn, P., Lolas, F., y Salazar, J.M. (2004) El Mercado y la educación superior. Calidad en la Educación 20, pp. 197-209.

Lolas, F. (1997) Universidad: polisemia, aporías, metáforas. En: Diálogo sobre Universidad. Santiago de Chile: Cuadernos Rector Juvenal Hernández, $\mathrm{N}^{\circ}$ 3, Corporación Cultural Rector Juvenal Hernández, pp. 33-42.

Lolas, F. (1996) Las universidades chilenas y sus entornos: dilemas y problemas. En Riveros, L. y Sapag, N. (editores) Retos y dilemas de la gestión universitaria. Santiago de Chile: Universidad de Chile, Facultad de Ciencias Económicas y Administrativas, pp. 45-56. 
Lolas, F. (2004a) Educación superior: valores fundamentales, dilemas permanentes. Anales de la Universidad de Chile, Sexta Serie, 16, pp. 33-48.

Lolas, F. (2004b) La educación superior chilena en tiempos de decisión. Anales del Instituto de Chile XXIV (2), pp. 69-81.

Recibido: 8 de mayo de 2006 Aceptado: 23 de mayo de 2006 